\title{
Planejamento da enfermagem frente à COVID-19 numa estratégia de saúde da família: relato de experiência
}

\author{
Nursing planning in front of COVID-19 in a family health strategy: experience report \\ Planificación de enfermería frente al COVID-19 en una estrategia de salud familiar: informe de experiencia
}

\begin{abstract}
RESUMO
Objetivo: Delinear uma experiência de planejamento organizacional da enfermagem junto à sua equipe da Estratégia de Saúde da Família VII, frente à pandemia da COVID-19. Método: Estudo descritivo de relato de experiência, que retrata as estratégias organizacionais construídas para atendimento nas Unidades de Saúde da Família, que compõem a referida Estratégia, localizada na zona rural do município de Igreja Nova, AL, Brasil. Resultados: Foram elaboradas três estratégias de atendimento dos casos suspeitos do novo Coronavírus, nos eixos: "Orientação da comunidade sobre o problema com sensibilização para ações de prevenção e promoção da saúde", "Educação Permanente em Saúde na equipe da ESF" e "Organização da oferta dos serviços de saúde prestados pela USF frente a pandemia". Entretanto, procurou-se manter o atendimento aos programas especiais, já desenvolvidos nestas unidades de saúde, para evitar danos à comunidade. Conclusão: As estratégias implementadas foram indispensáveis, pela função que a Atenção Primária em Saúde desempenha dentro do Sistema Único de Saúde, porque instrumentalizou os profissionais para o atendimento, definiu papéis e alinhou o discurso dos protagonistas da saúde para as orientações junto à comunidade.
\end{abstract}

DESCRITORES: Enfermagem; Atenção Primária à Saúde; Coronavírus; Vírus da SARS.

\section{ABSTRACT}

Objective: To delineate an experience of organizational planning in nursing with his team from the Family Health Strategy VII, facing the pandemic of COVID-19. Method: Descriptive study of an experience report, which portrays the organizational strategies built for care in the Family Health Units, which make up the referred Strategy, located in the rural area of the municipality of Igreja Nova, AL, Brazil. Results: Three strategies for dealing with suspected cases of the new Coronavirus were elaborated, in the following axes: "Community orientation on the problem with awareness for prevention and health promotion actions", "Permanent Health Education in the FHS team" and "Organization the supply of health services provided by the USF in the face of the pandemic ". However, efforts were made to maintain attendance to special programs, already developed in these health units, to avoid damage to the community. Conclusion: The strategies implemented were indispensable, due to the role that Primary Health Care plays within the Unified Health System, because it instrumentalized the professionals to provide care, defined roles and aligned the discourse of the health protagonists to the guidelines with the community.

DESCRIPTORS: Nursing; Primary Health Care; Coronavirus; SARS Virus.

\section{RESUMEN}

Objetivo: Delinear una experiencia de planificación organizacional en enfermería con su equipo a partir de la Estrategia de Salud Familiar VII, frente a la pandemia COVID-19. Método: Estudio descriptivo de un informe de experiencia, que retrata las estrategias organizacionales creadas para la atención en las Unidades de Salud de la Familia, que conforman la referida Estrategia, ubicada en el área rural del municipio de Igreja Nova, AL, Brasil. Resultados: se elaboraron tres estrategias para tratar casos sospechosos del nuevo Coronavirus, en los siguientes ejes: "Orientación comunitaria sobre el problema con conciencia para acciones de prevención y promoción de la salud", "Educación permanente en salud en el equipo de FHS" y "Organización el suministro de servicios de salud proporcionados por la USF ante la pandemia ". Sin embargo, se hicieron esfuerzos para mantener la asistencia a programas especiales, ya desarrollados en estas unidades de salud, para evitar daños a la comunidad. Conclusión: Las estrategias implementadas fueron indispensables, debido al papel que desempeña la Atención Primaria de Salud dentro del Sistema Único de Salud, ya que instrumentalizó a los profesionales para brindar atención, definió roles y alineó el discurso de los protagonistas de salud con las pautas con la comunidad.

DESCRIPTORES: Enfermería; Atención Primaria de Salud; Coronavirus; Virus del SARS.

RECEBIDO EM: 15/06/2020 APROVADO EM: 16/06/2020 


\section{Daniglayse Santos Vieira}

Enfermeira da Estratégia de Saúde da Família. Mestranda em Enfermagem pela Universidade Federal de Alagoas. https://orcid. org/0000-0002-10887-1594

\section{Patrícia Cavalcante de Sá}

Enfermeira. Docente do Curso Subsequente de Técnico em Enfermagem do Campus Benedito Bentes/Instituto Federal de Alagoas. Mestre em Ensino na Saúde pela Universidade Federal de Alagoas. https://orcid.org/0000-0002-8449-0750

\section{Roberta Carozo Torres}

Enfermeira. Docente do Curso Subsequente de Técnico em Enfermagem do Campus Benedito Bentes/Instituto Federal de Alagoas. Mestra em Enfermagem pela Universidade Federal de Sergipe. https://orcid.org/0000-0003-1144-9885

\section{Fabianny Torres de Oliveira}

Enfermeira Assistente do Hospital Universitário Prof. Alberto Antunes. Mestranda em Enfermagem pela Universidade Federal de Alagoas. https://orcid.org/0000-0001-6193-2002

\section{Kely Regina da Silva Lima Rocha}

Enfermeira. Docente do Curso Subsequente de Técnico em Enfermagem do Campus Benedito Bentes/Instituto Federal de Alagoas. Mestra em Enfermagem pela Universidade Federal de Alagoas. https://orcid.org/0000-0002-6937-898X

\section{Talita Lúcio Chaves Vasconcelos}

Enfermeira. Docente do Curso Subsequente de Técnico em Enfermagem do Campus Benedito Bentes/Instituto Federal de Alagoas. Mestra em Enfermagem pela Universidade Federal de Alagoas. https://orcid.org/0000-0001-8751-6525

\section{Maria Lysete de Assis Bastos}

Enfermeira. Docente do Programa de Pós Graduação em Enfermagem da Universidade Federal de Alagoas e Docente do Curso Subsequente de Técnico em Enfermagem do Campus Benedito Bentes/Instituto Federal de Alagoas. Doutora em Ciências/ Biotecnologia pela Universidade Federal de Alagoas. https://orcid.org/0000-0003-1752-7645

\section{INTRODUÇÃO}

$\mathbf{N}$ o quarto trimestre de 2019, o mundo se deparou com um novo patógeno de fácil disseminação, infectando grande número de pessoas, de forma rápida. O novo vírus despertou a atenção da comunidade científica, a fim de aliar esforços ao combate de uma doença que ainda está escrevendo sua história natural no homem ${ }^{(1)}$. Coronavírus é uma família de vírus que causa infecçôes respiratórias e sua descoberta em humanos teve início em 1965, com a identificação da presença deste vírus em trato respiratório de adultos com resfriado comum. A microscopia eletrônica deste mostrava uma imagem semelhante a uma coroa, sendo descrito como Coronavírus, em decorrência desse perfil na microscópico ${ }^{(2)}$.

Estudo com o novo agente etiológico da síndrome respiratória grave registrada na China constatou que o genoma do 2019-nCoV tem $89 \%$ de identidade de nucleotídeos com o SARS do tipo morcego-CoVZXC21 e $82 \%$ com o do SARS-CoV humano. Esses achados apontam a origem e a evolução desta nova linhagem betacoronavírus $^{(3)}$. O SARS-CoV-2 é capaz de provocar a doença classificada como COVID-19, apresenta alta transmissibilidade e provoca uma síndrome respiratória aguda que varia cerca de $80 \%$ para casos leves e entre $5 \%$ e $10 \%$ dos casos evoluem para insuficiência respiratória grave ${ }^{(4)}$.

Frente à epidemia chinesa que se disseminava rapidamente com severidade e grande dificuldade para controle, a Organização Mundial da Saúde (OMS) declarou, em 11 de março de 2020, que se tratava de uma pandemia. Assim, convoca os países a empreenderem esforços para contenção do surto e tentar diminuir a letalidade mundial. No Brasil, em 22 de janeiro de 2020, foi ativado o Centro de Operações de Emergências em Saúde Pública para o novo Coronavírus (COE COVID-19), estratégia prevista no Plano Nacional de Resposta às Emergências em Saúde Pública do Ministério da Saúde ${ }^{(4)}$.

No cenário de pandemia, destaca-se a Estratégia de Saúde da Família (ESF) como porta de entrada do Sistema Único de Saúde
(SUS), com papel fundamental na resposta global à doença em questão, por ofertar atendimento à população e subsidiar a avaliação da saúde comunitária. Diante do cenário desconhecido da pandemia da COVID-19, faz-se necessário estruturar o serviço de saúde para que o usuário possa encontrar na Unidade de Saúde da Família (USF) de referência um acolhimento que fortaleça a relação entre ele e o profissional de saúde, cumprindo-se, assim, a Política Nacional de Humanizaçãoo ${ }^{(5)}$.

Assim, faz-se necessário pensar, entre tantas estratégias, formas de acesso às unidades básicas de saúde que garantam segurança às pessoas, além da organização de demanda para evitar a contaminação cruzada entre as já instituídas e as novas instauradas. Neste panorama, a enfermagem encontra-se na linha de frente do atendimento à COVID-19, com a função de desempenhar técnicas e estratégicas de prevenção e promoção da saúde, junto à comunidade assistida, para o combate a pandemia ${ }^{(6,7)}$.

Acredita-se que trazer ao conhecimento da comunidade o trabalho desenvolvido pela enfermagem, é contribuir com outros profis- 
sionais que enfrentam as mesmas realidades e desafios e encorajá-los para o aumento da batalha contra o vírus. Desse modo, o presente relato objetivou delinear uma experiência de planejamento de intervenção organizacional da enfermagem junto à sua equipe da ESF frente à pandemia da COVID-19.

\section{METODOLOGIA}

Estudo descritivo de relato de experiência que retrata uma intervenção organizacional junto à ESF VII, localizada na zona rural do município de Igreja Nova, Alagoas, Brasil. Essa ESF concentra em sua área adscrita oito povoados (Capim grosso, Sítio novo, Fazenda nova, Cotovelo, Olho d'água do taboado, Lagoa do gado bravo, Jenipapo e Santiago), no quais atende a 2.478 pessoas cadastradas. A referida ESF possui três USF. Sua equipe é composta por: sete agentes comunitários de saúde, três técnicos de enfermagem, uma enfermeira, uma dentista, um médico, uma auxiliar de saúde bucal, três auxiliares de serviços gerais, uma auxiliar administrativa e um motorista. Vale ressaltar que as USF alocam de forma fixa os profissionais de nível médio, equitativamente, enquanto os profissionais de nível superior, o motorista e a auxiliar de saúde bucal trabalham em forma de rodízio, conforme cronograma da Secretaria Municipal de Saúde do referido município.

A abordagem das intervenções educativas ocorreu mediante um planejamento prévio para conhecer as necessidades deste público-alvo, diante dos cuidados que devem ser dispensados para os profissionais de saúde e para a comunidade frente à pandemia da COVID-19. De posse das necessidades detectadas, a ação intervencionista foi dividida em duas fases. A primeira ocorreu no período de 16 a 18 de março de 2020 ,

\begin{tabular}{l} 
Quadro 1. Ações pontuais Igreja Nova, AL, Brasil. 2020. \\
AçõES PONTUAIS DE PROMOção E PREVENÇão \\
1. Solicitação do isolamento social \\
\hline 2. Lavagem das mãos com água e sabão \\
3. Evitar locais aglomerados \\
4. Evitar tocar olhos, boca e nariz \\
\hline 5. Não usar medicamentos por conta própria \\
\hline 6. Evitar contatos com pessoas que estejam com sintomas de gripe \\
\hline 7. Comunicar ao receber visita de pessoas oriundas de locais com casos notificados \\
\hline
\end{tabular}

\section{Quadro 2. Estratégias para as ações. Igreja Nova, AL, Brasil. 2020.}

ESTRATÉGIAS PARA AS AÇõES DE PROMOÇÃO E PREVENÇÃO

1. Demonstração prática de como higienizar as mãos

2. Orientação sobre o uso da água sanitária e do hipoclorito de sódio

3. Orientação sobre o uso do álcool a $70 \%$

4. Demonstração prática do uso da máscara

5. Orientação sobre a confecção de máscara de tecido e o seu uso

6. Disponibilização de uma comunicação telefônica para esclarecimento de dúvidas da comunidade sobre o Coronavírus

7. Circulação de carro de som alertando as pessoas sobre o risco da doença e informando da importância do isolamento social

8. Distribuição de panfletos de linguagem acessível e lúdica para a comunidade sobre a COVID-19 e a forma de proteção

9. Comunicar ao receber visita de pessoas oriundas de locais com casos notificados com um total de cinco horas de treinamento, em cada USF, destinado aos profissionais de nível médio, como forma de alinhar as ações propostas dentro do território da ESF VII. Já na segunda, realizou-se no período de 19 de março a 10 de abril de 2020, perfazendo um total de 32 horas de palestras, distribuídas nos oito povoados que compõem esta ESF, o que representou dois encontros por povoado. Para tanto, foram adotadas estratégias educativas que envolveram os profissionais de saúde e as comunidades, com abordagem metodológica, para rompimento da cadeia de transmissibilidade do vírus.

\section{RELATO DA EXPERIÊNCIA}

\section{Orientação da comunidade sobre o pro- blema com sensibilização para ações de prevenção e promoção da saúde}

$\mathrm{O}$ confinamento de doentes devido às enfermidades infectocontagiosas é uma estratégia antiga, entretanto, a globalização tem facilitado a dispersão de patógenos que levam a pandemias, o que torna complexa a contenção das infecções, como foi o caso da Zika e H1N1, entre outras doenças. A atual pandemia restringiu o cidadão ao aperto de mão, ao abraço caloroso e ao beijo singelo, e aglomerações, neste momento, não são permitidas. Estas medidas foram reforçadas por meio de decretos emitidos por estados e municípios, no sentido de evitar a propagação da COVID-19 ${ }^{(8)}$.

A primeira medida adotada foi a orientação e o esclarecimento à comunidade sobre a problemática que estava acometendo outras partes do mundo e no Brasil. Inicialmente, foi preciso instruir que as pessoas ao apresentarem sintomas gripais acompanhados de febre, procurassem o posto de saúde. Para tanto, a USF deveria estar bem organizada e seus profissionais bem informados. Dessa maneira, algumas medidas foram tomadas com respeito e adequação à realidade local e às recomendações do Manual do Ministério da Saúde para que a comunidade tivesse acesso à informação frente à pandemia (Quadro 1).

Para que as ações tivessem impactos positivos na comunidade, foi preciso elaborar e executar estratégias para as ações de promoção e prevenção apresentadas no Quadro 2. 
Educação Permanente em Saúde na equipe da ESF

Para consolidar o trabalho em equipe na área da saúde, foi necessário estabelecer objetivos e metas bem definidas e comuns ao grupo de profissionais, para o crescimento individual e do grupo, para contribuir com o desenvolvimento de um cuidado centrado no usuário e na sua comunidade ${ }^{(9)}$. Assim, precisou-se mobilizar a equipe para uma visão reflexiva do trabalho em saúde frente à COVID-19. Nesse sentido, realizou-se uma educação permanente em saúde, conforme proposta do Ministério da Saúde, tomando como referência a Portaria de Consolidação n. ${ }^{\circ}$ 02, de 28 de setembro de 2017, para nortear a formação e a qualificação dos profissionais da ESF VII, com vistas a melhorar suas práticas profissionais e a própria organização do trabalho com base nas necessidades e dificuldades do $S U S^{(10)}$.

Buscou-se capacitar os profissionais de nível médio por meio das metodologias ativas de ensino-aprendizagem, tais como: rodas de conversa, palestras interativas e atividades lúdicas. A capacitação foi conduzida pela Enfermeira e o Médico da ESF, tendo como locus a própria USF de atuação do profissional. Para garantir a participação efetiva deles, privilegiou-se a execução destas atividades no período da manhã. Além disso, também se levou em consideração o aspecto da aglomeração e o distanciamento necessário entre os membros da equipe.

As atividades em cada USF foram iniciadas com uma roda de conversa com os profissionais para entender suas percepções e conhecimento prévio sobre a temática. Na sequência, foi apresentado um vídeo retrospectivo sobre as principais pandemias que aconteceram no mundo para, assim, trazer à tona a pandemia da COVID-19. Durante a capacitação, buscou-se orientar os profissionais na identificação e manejo oportuno de casos suspeitos de infecção humana pelo vírus, sinais e sintomas da doença, recomendações a grupos especiais, isolamento social, desinfecção de objetos, segurança da equipe entre outros assuntos visando a
Cada local possui um

modelo de rotinas

e atendimentos

baseado no

levantamento

epidemiológico

prévio realizado antes

da implementação das

USF, para tanto, são

seguidos os modelos

de atenção básica

do Ministério da

Saúde. Dentro desta

equipe de saúde, $o$

enfermeiro da saúde

coletiva exerce sua

prática em diversas

áreas, dentre elas,

encontra-se a técnico-

administrativa,

desenvolvendo

atividades de

gerenciamento da

$\operatorname{ESF}^{(11)}$. redução dos riscos de transmissão, dentro da USF e na comunidade.

A capacitação consistiu em orientar o papel que cada profissional, dentro de suas atribuições, deveria desenvolver diante desta pandemia. Foi apresentado o conceito de acolhimento, sua importância e as habilidades necessárias para que seja feito de forma adequada. Além disso, o treinamento contou com duas atividades práticas que foram: a paramentação e desparamentação dos Equipamentos de Proteção Individual (EPI), bem como se portar frente ao acolhimento do sintomático respiratório suspeito de COVID-19 que procurasse a unidade de saúde. No final de cada capacitação foi destinado um momento para perguntas e esclarecimentos de dúvidas dos participantes.

Organização da oferta dos serviços de saúde prestados pela USF frente à pandemia

Cada local possui um modelo de rotinas e atendimentos baseado no levantamento epidemiológico prévio realizado antes da implementação das USF, para tanto, são seguidos os modelos de atenção básica do Ministério da Saúde. Dentro desta equipe de saúde, o enfermeiro da saúde coletiva exerce sua prática em diversas áreas, dentre elas, encontra-se a técnico-administrativa, desenvolvendo atividades de gerenciamento da $\operatorname{ESF}^{(11)}$.

Diante da situação vivenciada, foi preciso reestruturar a oferta dos serviços de saúde em meio à pandemia, sem esquecer os princípios de integralidade, equidade e universalidade que regem o SUS. Assim, tomou-se como base para essas ações, as informações divulgadas pelas autoridades sanitárias. Sabe-se que o vírus é transmitido, principalmente, através de gotículas geradas quando uma pessoa infectada tosse, espirra ou fala. Essas gotículas são muito pesadas para ficar no ar. Elas caem rapidamente em pisos ou superfícies. Assim, a pessoa pode ser infectada respirando o vírus se estiver a menos de um metro de uma pessoa que tem COVID-19 ou ao tocar em uma superfície contaminada e, em seguida, seus olhos, nariz ou boca 
antes de lavar as mãos ${ }^{(12)}$.

Diante desta forma de transmissão, a primeira coisa a ser definida foi o local onde aconteceria o atendimento aos casos suspeitos. Logo, foi definida uma sala de observação exclusiva em cada USF que apresentasse uma boa ventilação para atender pessoas com quadro clínico de sintomas respiratórios para avaliação. Essa sala foi equipada com: uma maca, um suporte de soro, alguns medicamentos de urgência, um termômetro, um esfigmomanômetro, um estetoscópio, um oxímetro digital, alguns insumos como seringas, algodão, álcool em gel entre outros, EPIs e um torpedo de oxigênio. Para maior segurança, a sala foi identificada com uma placa na porta a fim de sinalizar como sala reservada.

A próxima etapa consistiu em organizar os atendimentos dos Programas atendidos pela ESF como hiperdia (atendimento a hipertensos e diabéticos), planejamento familiar, puericultura (crescimento e desenvolvimento), pré-natal, vacinação, exame Papanicolau, dentre outros procedimentos e serviços oferecidos. Para tanto, foi reestruturada a oferta do serviço para nortear os profissionais da equipe e usuários de acordo com suas buscas. Ao pensar no grupo de risco para infecção por COVID-19, chamou a atenção para haver um cuidado maior com pacientes com hipertensão, os que têm doenças cardiovasculares, bem como outras doenças crônicas, como diabetes, pois existe uma alta prevalência de pacientes cadastrados na área de abrangência portadores destas patologias, que são fatores de agravamento do quadro clínico caso essa pessoa seja infectada pelo vírus.

Ao pensar neste público-alvo cadastrado no programa do hiperdia (hipertensos e diabéticos), foi adequada a distribuição dos remédios durante o período da quarentena a fim de assegurar a continuidade do tratamento. Dessa forma, ficou restrito a atendimentos nas USFs com agendamento prévio, os casos nos quais os valores da pressão arterial e nível glicêmico estivessem descompensados na última consulta realizada. Para o planejamento familiar, a distribuição dos anticoncepcionais e preservativo masculino não foi interrompida. A manutenção do calendário básico de vacinação do recém-nascido até os quatro anos de idade foi preservada, utilizando-se a vacinação em domicílio com agenda-

Figura 1. Fluxograma do atendimento aos sintomas gripais. Igreja Nova, $A L$, Brasil. 2020.

Caso suspeito COVID-19 chega a USF

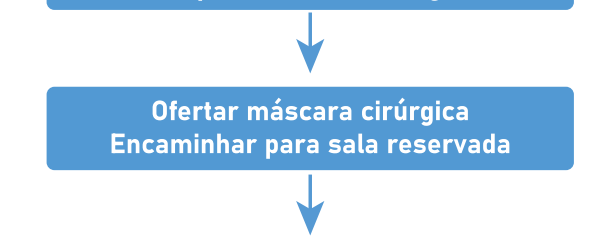

Paramentação do profissional para atendimento

Triagem Enfermagem

Consulta Médica

Isolamento domiciliar e

orientações para casos leves

Encaminhar ao serviço de emergência para casos graves mento prévio, para evitar aglomerações na USF e exposições das pessoas ao vírus. As vacinas foram aplicadas conforme normas de conservação e técnica de administração recomendadas.

Para estruturação do atendimento no programa do Pré-natal às gestantes, independentes da idade gestacional, tiveram seus atendimentos preservados na unidade de saúde, porém, essas consultas foram agendadas por horários individuais. Vale salientar que de acordo com estudos científicos realizados na China, não há muitas informações sobre o impacto da doença em grávidas e recém-nascidos. No entanto, na China não foi observado nada semelhante ao impacto que a Zika causou no Brasil em 2015, no que diz respeito ao binômio mãe-filho. Porém, o bebê nascido de mãe com COVID-19 deve ser mantido em quarentena ${ }^{(13,14)}$.

Para o puerpério, a rotina foi preserva$\mathrm{da}$ visto que realiza-se a visita domiciliar da mãe e do recém-nascido para prestar e orientar cuidados necessários, como orientações sobre amamentação, higiene do bebê, cuidados com a ferida operatória, repouso, realização do teste do pezinho do bebê, entre outros, para garantir a saúde de ambos nesta fase inicial.

Seguindo a atribuição e prerrogativa da Política Nacional de Atenção às Urgências, o acolhimento e atendimento de baixa gravidade/complexidade serão realizados na USF e os casos julgados de maior gravidade serão encaminhados aos hospitais de referência. Em situações em que não se encaixam nas anteriores, disponibilizou-se a opção de comunicação telefônica entre comunidade e equipe de saúde, para esclarecer sintomas sobre a COVID-19, bem como outras situações que envolvessem o processo saúde-doença.

Para os agentes comunitários de saúde foi orientado durante seu trabalho de campo seguir as recomendações para adequações das ações frente ao Coronavírus, contidas na publicação do Ministério da Saúde, onde uma das competências é continuar realizando as visitas domiciliares, principalmente na busca ativa de casos suspeitos, porém a visita é 


\section{artigo}

Vieira, D.S.; Sá, P.C.; Torres, R.C.; Oliveira, F.T.; Rocha. K.R.S.L.;Vasconcelos, T.L.C.; Bastos, M.L.A.;

Planejamento da enfermagem frente à covid-19 numa estratégia de saúde da familia: relato de experiência

limitada na área peri domiciliar em lugares com boa ventilação.

\section{0 atendimento na USF aos casos suspeitos de COVID-19}

Sendo a APS a porta de entrada, foi elaborada uma estratégia para atendimentos de casos com suspeita de infecção pela COVID-19, fundamentada no Procedimento Operacional Padrão do Ministério da Saúde, cujos objetivos eram: padronizar ações para a detecção precoce de pessoas suspeitas de infecção pelo novo coronavírus (2019-nCoV); realizar manejo inicial; acionar transporte e encaminhar casos suspeitos para a unidade de referência de forma oportuna e segura; registrar informações clínicas, histórico de viagem internacional ou contato com caso suspeito ou confirmado; investigar e registrar dados de contatos próximos; realizar a notificação imediata; adotar medidas para evi- tar casos graves e óbitos; e orientar a população sobre medidas de prevenção ${ }^{(5)}$.

Foi determinado que, ao chegar na USF, esse paciente, considerado caso suspeito, seria encaminhado para a sala reservada adaptada para esse tipo de atendimento, e realizada a consulta de enfermagem. Para isso, foi utilizado um instrumento de consulta que possibilitasse um olhar ampliado do processo saúde-doença do paciente com fins a facilitar a identificação dos problemas e as decisões a serem tomadas. Em seguida, o paciente passaria pela avaliação médica, seguindo o fluxograma recomendado pelo Ministério da Saúde (Figura 1)

A depender dos sintomas, o paciente seria encaminhado para isolamento domiciliar e continuaria sendo monitorado ou seria encaminhado para um serviço de emergência em caso de agravamento dos sintomas. Para atendimento dos casos suspeitos, os profissionais devem estar com paramentação completa (capote ou avental manga longa, gorro, propés, óculos, máscaras, protetor facial e luvas) de acordo com o documento do Ministério da Saúde para recomendações de proteção aos trabalhadores dos serviços de saúde no atendimento de COVID-19 e outras síndromes gripais. Para os demais atendimentos que não se caracterizam como suspeitos para o coronavírus foi instituído manter uma distância de no mínimo um metro e uso de máscara cirúrgica.

\section{CONCLUSÃO}

As estratégias organizacionais implementadas em tempos de pandemia foram indispensáveis, pela função que a APS desempenha dentro do SUS, porque instrumentalizou os profissionais para o atendimento, definiu papéis e alinhou o discurso dos protagonistas da saúde para as orientações junto à comunidade da ESF VII.

\section{REFERÊNCIAS}

1. Chen N, Zhou M, Dong X, Qu J, Gong F, Han Y, et al Epidemiological and clinical characteristics of 99 cases of 2019 novel coronavirus pneumonia in Wuhan, China: a descriptive study. The Lancet. 2020; 395:507-513.

2. Kahn JS, McIntosh K. History and Recent Advances in Coronavirus Discovery. The Pediatric Infectious Disease Journal. 2005 Nov; 24(11).

3. Chan JF, Kok KH, Zhu Z, Chu H, Para KKW, Yan S, et al. Genomic characterization of the 2019 novel human-pathogenic coronavirus isolated from a patient with atypical pneumonia after visiting Wuhan. Emerg Microbes Infect. 2020; 9(1):221 236.

4. Ministério da Saúde, Secretaria de Atenção Especializada à Saúde, Departamento de Atenção Hospitalar, Domiciliar e de Urgência (BR). Protocolo de manejo clínico da COVID-19 na Atenção Especializada. Brasília (DF): MS, 2020.

5. Ministério da Saúde, Secretaria de Atenção Primária a Saúde (BR). Procedimento Operacional Padronizado: equipamento de proteção individual e segurança no trabalho para profissionais de saúde da APS no atendimento às pessoas com suspeita ou infecção pelo novo coronavírus (COVID-19). Brasília (DF): MS, 2020.

6. Souza LPS, Souza AG. Enfermagem brasileira na linha de frente contra o novo Coronavírus: quem cuidará de quem cuida? J. nurs. health. 2020;10(Esp).

7. Barbosa SP. A atenção primária à saúde no contexto da COVID-19. HU Rev. 2020; 46:1-2.
8. Ornell F, Schuch JB, Sordi, AO, Kessler FHP. Medo pandêmico e COVID-19: ônus e estratégias de saúde mental. Braz. J. Psiquiatria [online]. 2020; 42(3):232-35.

9. Agreli FH, Peduzzi M, Bailey C. The relationship between team climate and interprofessional collaboration: preliminary results of a mixed methods study. J Interprof Care. 2017 Mar; 31(2):184186.

10. Ministério da Saúde (BR). Portaria de Consolidação n. ${ }^{\circ}$ 02/2017. Dispõe sobre a Política Nacional de Educação Permanente em Saúde como estratégia do SUS para formação e desenvolvimento de trabalhadores para o setor. DOU. Brasília (DF): MS, 2017.

11. Ministério da Saúde (BR). Portaria n. ${ }^{\circ}$ 2.436/2017. Aprova a Política Nacional de Atenção Básica,estabelecendo a revisão de diretrizespara a organização da Atenção Básica, no âmbito do Sistema Único de Saúde(SUS). Brasília (DF): MS, 2017.

12. World Health Organization. Report of the WHO-China Joint Mission on Coronavirus Disease 2019 (COVID-19). Genebra: WHO, 2020

13. Santos VML, Santos Jr JEd, Huller KS, Cardozo JMOTF. Correlation Study Between Indicators from Prospective Studies of Coronavirus, H1N1, H5N1, H2N2, H3N2 and Zika. Cad. Prospecção. 2020; 13(2):576-96,.

14. Oliveira CS, Vasconcelos PFC. Microcephaly and Zika virus. J Pediatr (Rio J). 2016; 92:103-5. 